\title{
A Retrospective Analysis of Provider-to-Patient Secure Messages: How Much Are They Increasing, Who Is Doing the Work, and Is the Work Happening After Hours?
}

Frederick North ${ }^{1}$, MD; Kristine E Luhman ${ }^{2}$, RN, MBA; Eric A Mallmann ${ }^{3}$, BA; Toby J Mallmann ${ }^{3}$, BSN; Sidna M Tulledge-Scheitel ${ }^{1}$, MD, MPH; Emily J North ${ }^{4}$, MD; Jennifer L Pecina ${ }^{5}$, MD

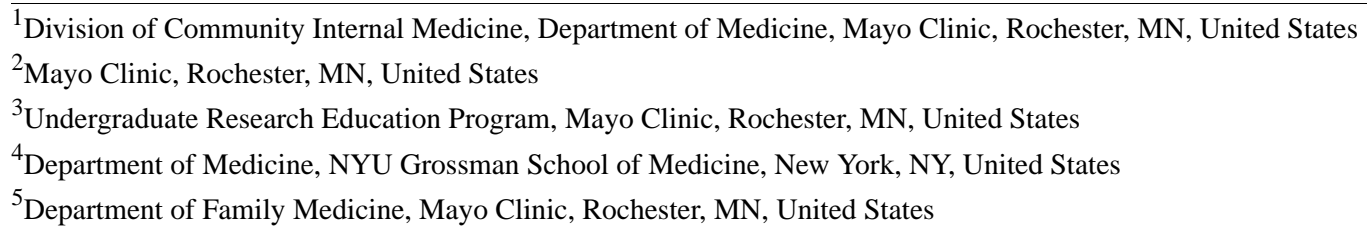

\section{Corresponding Author:}

Frederick North, MD

Division of Community Internal Medicine

Department of Medicine

Mayo Clinic

200 First Street SW

Rochester, MN, 55905

United States

Phone: 15072842511

Email: north.frederick@mayo.edu

\section{Abstract}

Background: Patient portal registration and the use of secure messaging are increasing. However, little is known about how the work of responding to and initiating patient messages is distributed among care team members and how these messages may affect work after hours.

Objective: This study aimed to examine the growth of secure messages and determine how the work of provider responses to patient-initiated secure messages and provider-initiated secure messages is distributed across care teams and across work and after-work hours.

Methods: We collected secure messages sent from providers from January 1, 2013, to March 15, 2018, at Mayo Clinic, Rochester, Minnesota, both in response to patient secure messages and provider-initiated secure messages. We examined counts of messages over time, how the work of responding to messages and initiating messages was distributed among health care workers, messages sent per provider, messages per unique patient, and when the work was completed (proportion of messages sent after standard work hours).

Results: Portal registration for patients having clinic visits increased from $33 \%$ to $62 \%$, and increasingly more patients and providers were engaged in messaging. Provider message responses to individual patients increased significantly in both primary care and specialty practices. Message responses per specialty physician provider increased from 15 responses per provider per year to 53 responses per provider per year from 2013 to 2018, resulting in a 253\% increase. Primary care physician message responses increased from 153 per provider per year to 322 from 2013 to 2018, resulting in a 110\% increase. Physicians, nurse practitioners, physician assistants, and registered nurses, all contributed to the substantial increases in the number of messages sent.

Conclusions: Provider-sent secure messages at a large health care institution have increased substantially since implementation of secure messaging between patients and providers. The effort of responding to and initiating messages to patients was distributed across multiple provider categories. The percentage of message responses occurring after hours showed little substantial change over time compared with the overall increase in message volume. 


\section{KEYWORDS}

patient messages; secure messages; patient portal; provider messages; electronic health records; electronic mail; communication; patients; physicians; physician assistants; nurse practitioners; nurses

\section{Introduction}

\section{Background}

The volume of secure messages in health care institutions is increasing. A major national survey in 2013 found that $29.6 \%$ of the US population had used the internet or email to communicate with a physician or a physician's office in the previous 12 months [1]. More recently, Lee et al [2] found that $37 \%$ of customers of a pharmacy chain reported contacting their physicians by email in the last 6 months.

Several health care systems in the United States have examined the increase in the number of messages from patients. Crotty et al [3] noted a tripling in messaging from 2001 to 2010. Cronin et al, Masterman et al, and Shenson et al [4-6] showed dramatic increases in message volumes across multiple specialties, including surgical and pediatric specialties.

Providers have mixed feelings about secure messages. In a survey of 43 clinicians across 5 clinics, $63 \%$ disagreed with the statement, "secure messaging reduces my workload," and 33\% agreed that "secure messaging has a negative effect on my workflow" [7]. However, 61\% agreed that "secure messaging has a positive effect on patient-clinician communication" [7].

\section{Objectives}

With providers responsible for an increasing number of secure messages, we looked at how secure messages to patients are distributed among staff at a large health care institution. In addition, with the increasing workload of secure messages, we examined whether there were potential work after work issues of using time after normal work hours to complete message responses [8].

\section{Methods}

\section{Setting}

The study took place at Mayo Clinic, Rochester, Minnesota, United States. Mayo Clinic is a multispecialty clinic with more than 1 million visits annually. There are more than 2200 physicians and scientists at the Rochester, Minnesota, campus.

Mayo Clinic started using Patient Online Services (POS; a secure patient portal) in 2010 for the primary care practice in Rochester, which serves a population of about 140,000 . The Mayo Clinic specialty practice started using POS in 2013. The Mayo Clinic specialty practice serves the local community of Rochester and takes referrals from other practices, both nationally and internationally.

The patient portal (POS) at Mayo Clinic gives patients the ability to view their laboratory results, radiology reports, medical images, office and hospital notes, and specialty consultations. In addition, POS has messaging capability for patients and providers to communicate asynchronously by sending messages through a secure server, which also sends these messages to the electronic health record (EHR). Patients must log in securely to POS to send a message. When providers initiate a message or respond to a patient-initiated message through POS, patients are notified by email. To protect privacy, the email notifying the patient of a provider message states that new information is available on their POS (portal) account. In the notification email, patients are given a link to the Mayo POS, but they still need to securely $\log$ in to their personal account to view and send these messages. These asynchronous POS messages between patients and providers are what we call secure messages.

Physicians, nurse practitioners (NPs), physician assistants (PAs), and registered nurses (RNs) can receive and respond to secure messages at Mayo Clinic. In addition, licensed practical nurses (LPN) and secretarial staff can also respond to and send secure messages to patients. The categories used in this paper were physician, NP/PA (combined NPs and PAs), RNs, and other (LPN and secretarial).

\section{Provider Secure Message Data Collection}

We collected all secure messages sent from the providers at Mayo Clinic, Rochester, from January 1, 2013, to March 15, 2018. The secure message dataset contained the clinic number of the patient, the date and time of day the provider sent the message, the message text, and the identification code of the provider or provider group who sent the message. In addition, the dataset was dichotomously categorized by whether the provider message was a response to a patient-initiated secure message or a provider-initiated secure message. The provider-response message was defined as a reply to a patient message. Provider-initiated messages were messages to patients created de novo by the provider (or created with help from software, as explained below in Abstraction of Provider Messages for Content). The entire secure message dataset contained only mutually exclusive provider-initiated and provider-response messages.

\section{Patient Demographics}

To examine the differences between patients who had provider-response messages during the initial time frame and those several years later, we examined demographics of the patients who initiated messages during the first 6 months of the study (January 1, 2013, to June 30,2013) and patients who initiated messages from the last 6 months (September 15, 2017, to March 15, 2018).

\section{Abstraction of Provider Messages for Content}

From a sampling period of October 2017 to February 2018, we randomized and abstracted 1200 messages, 100 each from 12 categories: 3 types of providers (physician, NP/PA, and RN) split into 2 different practices (primary care and specialty), split further into 2 different message types (response and provider initiated). This gave us the 1200 randomized messages of 100 each in 12 categories ( 3 provider types multiplied by 2 practice types multiplied by 2 message types). 
Across the 12 categories, we further dichotomously coded these as being automated or not. We categorized messages as automated if the content was completely software generated, such as reminders for screening mammograms and missed appointment notifications. There were other messages initiated that were not completely automated but did not have a personal message. For example, messages reaching out for specific laboratory or imaging tests that required provider input to order, but the message was not personalized to the point of explaining any details about the purpose of the tests. An example of this would be "Your provider has requested the following testing: fasting blood work in March. Please respond with your availability through Patient Online Services." These message types were also categorized as automated. Some messages from patients contained only an update that merely required an acknowledgment such as "thanks for the update." When abstracting the content, we also categorized the message responses as containing only an acknowledgment to account for these. Additional information collected was whether there was reference to having consulted another provider. This was to quantify the frequency at which messages could involve more than one provider. An example of this was a message from an NP/PA who wrote: "I spoke again to our C. diff specialist. He would like you to finish 10 days of vancomycin."

It should be noted that Mayo Clinic has a web-based knowledge system called Ask Mayo Expert, which has text-based content and care process algorithms to help with specific clinical questions. Ask Mayo Expert also gives a list of Mayo experts in specific areas. In this case, the NP/PA may have used Ask Mayo Expert to get the name of the Mayo expert in Clostridium difficile enteritis. It was outside the scope of this study to see how often providers were using resources such as Ask Mayo Expert (or other web-based resources) to answer patient questions.

\section{Portal Registration and Unique Face-to-Face Patient Visit Counts}

Portal registration information was obtained from the Mayo Clinic connected care data. The number of unique patients seen during face-to-face visits was obtained from the Mayo Clinic administrative data.

\section{Work After Work Measure}

From the date and time the secure message was completed, we determined whether the messages were sent during the usual business hours of 8 AM to 5 PM from Monday to Friday US central/daylight saving time.

\section{Statistical Analysis}

We used JMP version 13.1 statistical analysis software (SAS) for the descriptive statistics as well as for analysis of variance for the differences between messages per patient by year. We used the Cochran-Armitage trend test to examine the trends in proportions, such as the proportion of messages answered outside of Monday to Friday from 8 AM to 5 PM. JMP version 13.1 was used to randomize the selection of messages for abstraction.

\section{Ethics}

We excluded all messages from individuals who had not given research authorization. Mayo Clinic sites in Minnesota ask all patients for their research authorization, which is not specific to any individual study. This study was approved by the Mayo Clinic institutional review board (IRB 17-004807).

\section{Results}

\section{Message Distribution by Practice Type}

A total of 3,941,618 messages were sent by Mayo Clinic providers between January 1, 2013, and March 15, 2018, associated with 353,177 unique patients. We excluded $6.06 \%$ $(238,870 / 3,941,618)$ of the messages from patients who had not given research authorization. After exclusion of the patients without research authorization there were 326,805 unique patients to whom Mayo Clinic providers sent 3,702,748 messages over the study duration. Provider responses to patient-initiated messages accounted for $48.87 \%$ $(1,809,614 / 3,702,748)$ of the messages; provider-initiated messages accounted for $51.13 \%(1,893,134 / 3,702,748)$. The primary care practice accounted for $28.31 \%$ $(1,048,216 / 3,702,748)$ of the messages, and the specialty practices had $71.69 \%(2,654,532 / 3,702,748)$ of the messages. Primary care providers initiated $18.28 \%(676,674 / 3,702,748)$ of the messages and responded to $10.03 \%(371,542 / 3,702,748)$. Specialists initiated $32.85 \% \quad(1,216,460 / 3,702,748)$ and responded to $38.84 \%(1,438,072 / 3,702,748)$.

\section{Practice Volumes and Portal Registration Over Time}

The increase in message counts could not be explained by a large growth in patient visits. In fact, the number of unique patients with face-to-face visits each year remained relatively stable, from 365,943 in 2013 to 388,707 in 2017 resulting in a $6 \%$ increase. Portal registration in patients with appointments increased from $33 \%$ in 2013 to $62 \%$ in 2018.

\section{Patient Demographics}

Table 1 shows the demographics of the patients who initiated secure messages and had provider responses. The primary care population started portal messages in 2010, whereas specialty practice started in 2013. At least twice as many patient-initiated messages were sent by female patients in both the primary care and specialty practices in 2013 , and this female predominance persisted into 2018. Older age groups, especially those $\geq 65$ years, comprised an increasing proportion of the provider-response messages in 2018 compared with 2013. 
Table 1. Demographic comparisons of the patients who initiated messages and had provider responses from 2013 to 2018 by provider type (primary care or specialty).

\begin{tabular}{|c|c|c|c|c|c|c|}
\hline \multirow[t]{2}{*}{ Demographic } & \multicolumn{3}{|c|}{ Primary care response messages } & \multicolumn{3}{|c|}{ Specialty response messages } \\
\hline & $\begin{array}{l}\text { First } 6 \text { months } \\
(2013 ; \\
n=14,151), \mathrm{n}(\%)\end{array}$ & $\begin{array}{l}\text { Last } 6 \text { months }(2017 \text { - } \\
2018 ; n=53,931), n(\%)\end{array}$ & $P$ value $^{\mathrm{a}}$ & $\begin{array}{l}\text { First } 6 \text { months } \\
(2013 ; \\
\mathrm{n}=20,109), \mathrm{n}(\%)\end{array}$ & $\begin{array}{l}\text { Last } 6 \text { months }(2017- \\
2018 ; \mathrm{n}=115,725), \mathrm{n} \\
(\%)\end{array}$ & $P$ value $^{\mathrm{a}}$ \\
\hline \multicolumn{7}{|l|}{ Age group (years) } \\
\hline $0-17$ & $443(3.1)$ & $4094(7.6)$ & $<.001$ & $926(4.6)$ & $8095(7.0)$ & $<.001$ \\
\hline $18-34$ & $2951(20.9)$ & $9380(17.4)$ & $<.001$ & $4555(22.7)$ & $16,730(14.5)$ & $<.001$ \\
\hline $35-49$ & 3769 (26.6) & $13,796(25.6)$ & .01 & $5473(27.2)$ & $23,542(20.3)$ & $<.001$ \\
\hline $50-64$ & $4903(34.6)$ & $15,861(29.4)$ & $<.001$ & $6191(30.8)$ & $35,721(30.9)$ & .82 \\
\hline $65-79$ & $1801(12.7)$ & $8772(16.3)$ & $<.001$ & $2592(12.9)$ & $27,220(23.5)$ & $<.001$ \\
\hline$\geq 80$ & $278(2.0)$ & $2023(3.8)$ & $<.001$ & $360(1.8)$ & $4390(3.8)$ & $<.001$ \\
\hline \multicolumn{7}{|l|}{ Sex } \\
\hline Female & $9970(70.5)$ & $34,011(63.1)$ & $<.001$ & $13,670(68.0)$ & $65,798(56.9)$ & $<.001$ \\
\hline Male & $4175(29.5)$ & $19,915(36.9)$ & $<.001$ & $6427(32.0)$ & $49,898(43.1)$ & $<.001$ \\
\hline \multicolumn{7}{|l|}{ Race } \\
\hline White & $13,182(93.2)$ & 49,424 (91.6) & $<.001$ & $18,574(92.4)$ & $105,646(91.3)$ & $<.001$ \\
\hline Asian & $390(2.8)$ & $1655(3.1)$ & .05 & $535(2.7)$ & $2614(2.3)$ & $<.001$ \\
\hline Black & $151(1.1)$ & $709(1.3)$ & .02 & $207(1.0)$ & $1449(1.3)$ & .008 \\
\hline Other & $428(3.0)$ & $2143(4.0)$ & $<.001$ & $793(3.9)$ & $6016(5.2)$ & $<.001$ \\
\hline \multicolumn{7}{|l|}{ Ethnicity } \\
\hline Hispanic or Latino & $199(1.4)$ & $975(1.8)$ & .001 & $308(1.5)$ & $2255(1.9)$ & $<.001$ \\
\hline Not Hispanic or Latino & $13,641(96.4)$ & $51,382(95.3)$ & $<.001$ & $19,102(95.0)$ & $108,097(93.4)$ & $<.001$ \\
\hline Unknown/not disclosed & $311(2.2)$ & $1574(2.9)$ & $<.001$ & $699(3.5)$ & $5373(4.6)$ & $<.001$ \\
\hline \multicolumn{7}{|l|}{ Highest level of education } \\
\hline $\begin{array}{l}\text { Some postcollege graduate stud- } \\
\text { ies }\end{array}$ & $2251(15.9)$ & $11,448(21.2)$ & $<.001$ & $3526(17.5)$ & $28,092(24.3)$ & $<.001$ \\
\hline 4-year college graduate & $3752(26.5)$ & $9208(17.1)$ & $<.001$ & $5183(25.8)$ & $21,866(18.9)$ & $<.001$ \\
\hline Some college or 2-year degree & 2918 (20.6) & $19,690(36.5)$ & $<.001$ & 4155 (20.7) & $37,619(32.5)$ & $<.001$ \\
\hline High school graduate & $1454(10.3)$ & $6003(11.1)$ & .004 & 2127 (10.6) & $14,559(12.6)$ & $<.001$ \\
\hline $\begin{array}{l}\text { Some high school (did not gradu- } \\
\text { ate) }\end{array}$ & $234(1.7)$ & $1210(2.2)$ & $<.001$ & $358(1.8)$ & $992(0.9)$ & $<.001$ \\
\hline Eighth grade or less & $16(0.1)$ & $164(0.3)$ & $<.001$ & $36(0.2)$ & $505(0.4)$ & $<.001$ \\
\hline Unknown & $3526(24.9)$ & $6208(11.5)$ & $<.001$ & $4724(23.5)$ & $12,092(10.4)$ & $<.001$ \\
\hline \multicolumn{7}{|l|}{ Patient's home address } \\
\hline Minnesota & $13,059(92.3)$ & $52,663(97.6)$ & $<.001$ & $14,196(70.6)$ & $68,538(59.2)$ & $<.001$ \\
\hline Contiguous state & $357(2.5)$ & $651(1.2)$ & $<.001$ & $2053(10.2)$ & $20,585(17.8)$ & $<.001$ \\
\hline $\begin{array}{l}\text { Other (other US states and inter- } \\
\text { national) }\end{array}$ & $735(5.2)$ & $617(1.1)$ & $<.001$ & $3860(19.2)$ & $26,602(23.0)$ & $<.001$ \\
\hline
\end{tabular}

${ }^{\mathrm{a}}$ Null hypothesis (H0): within primary care or specialty, first 6 months demographic proportion=last 6 months demographic proportion.

\section{Message Counts Over Time}

Figure 1 shows the increase in provider messages from 2013 through 2017. Figure 2 shows the rise in distinct patients who received provider messages over the course of the study. Messages per unique patient increased over the 5-year course of the study (Figure 3), and the increase in both provider response to messages and provider-initiated messages per unique patient was statistically significant (Table 2). Figures 4 and 5 show the number of message responses per provider by year for primary care and specialty care. 
Figure 1. Message counts by year.

500,000

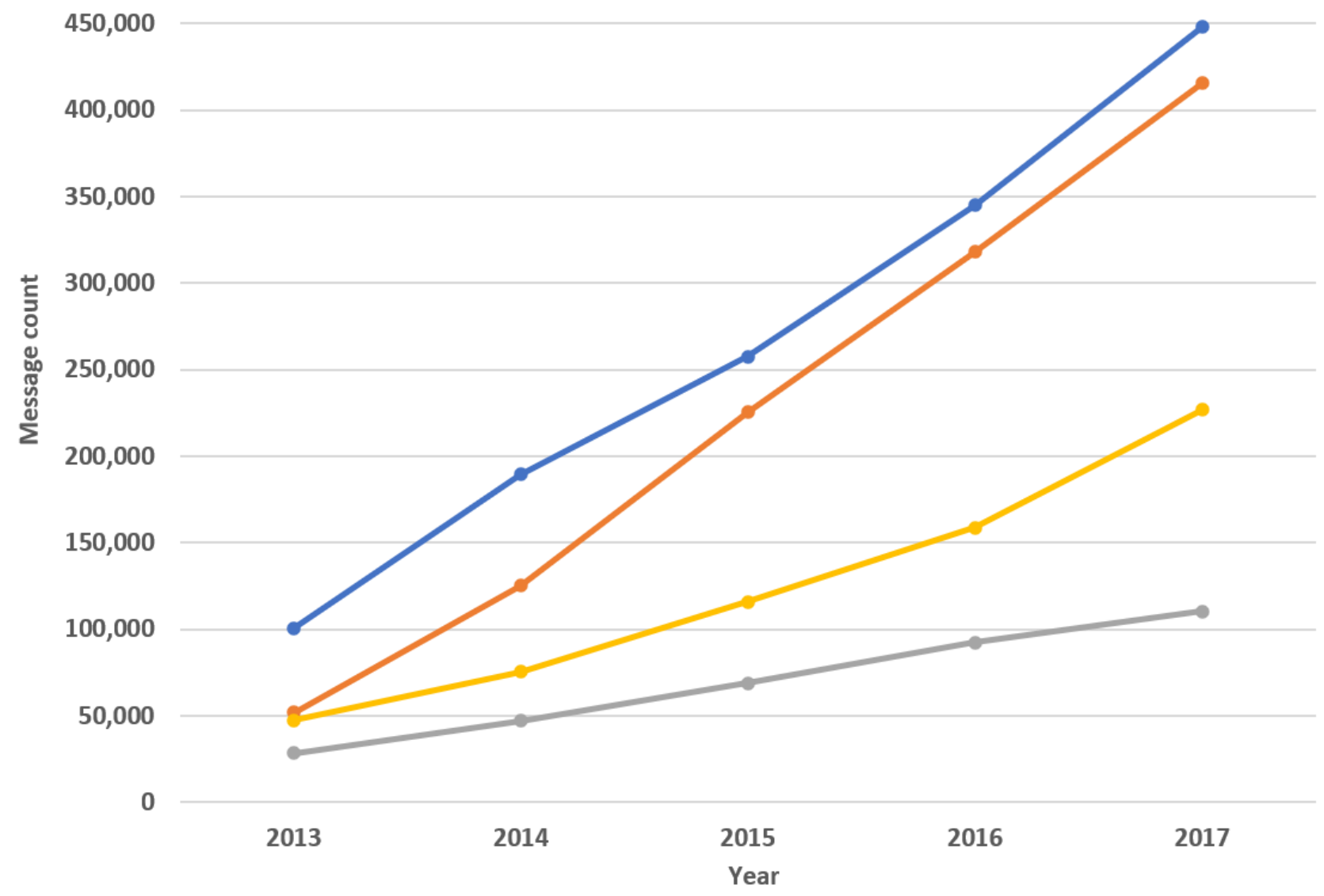

$\multimap$ Specialty response $\longrightarrow$ Specialty initiated $\multimap$ Primary care response $\multimap$ Primary care initiated 
Figure 2. Distinct patients generating a provider response or provider-initiated message by year.

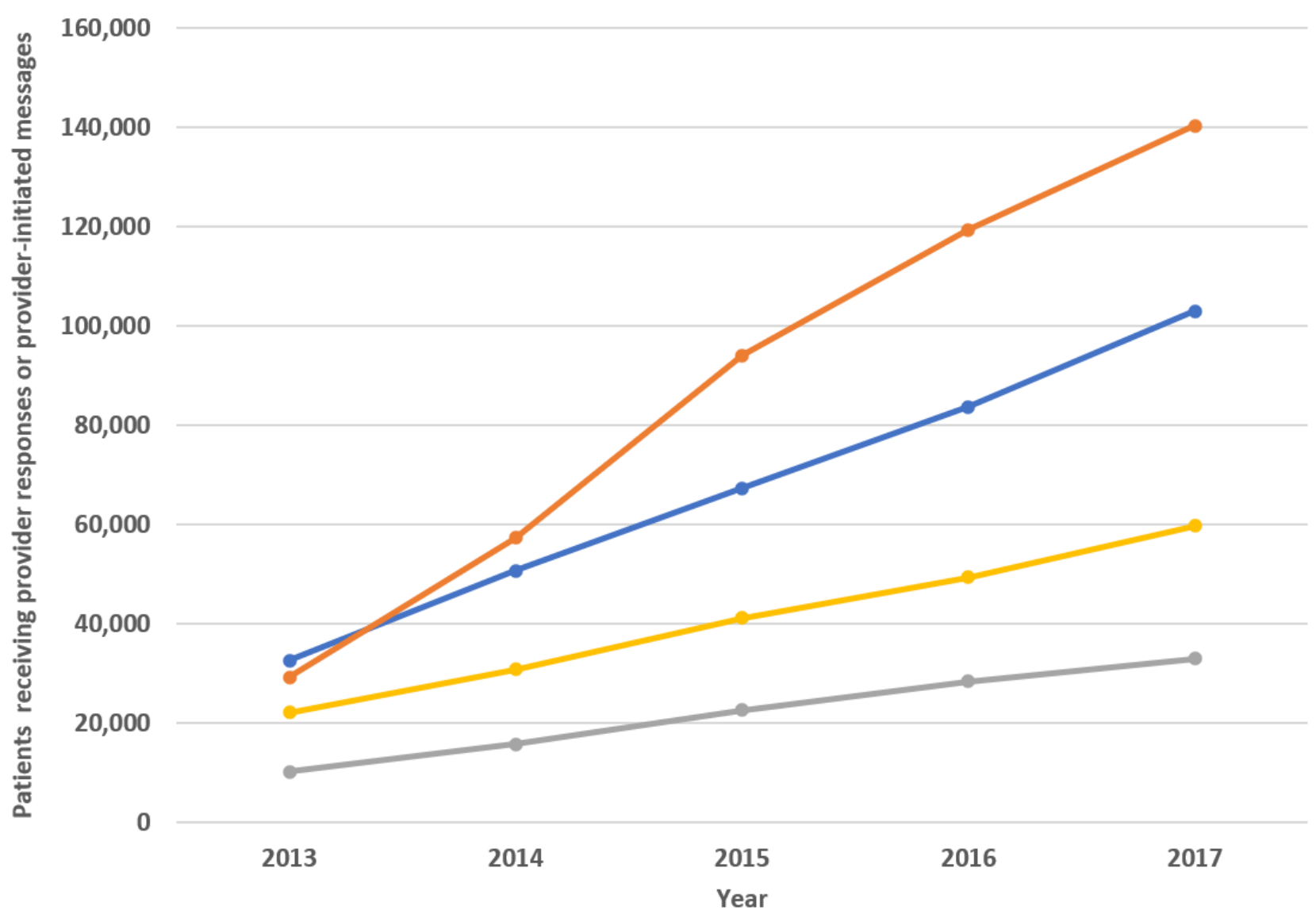

$\longrightarrow$ Specialty response $\longrightarrow$ Specialty initiated $\longrightarrow$ Primary care response $\longrightarrow$ Primary care initiated 
Figure 3. Message counts per unique patient by year.

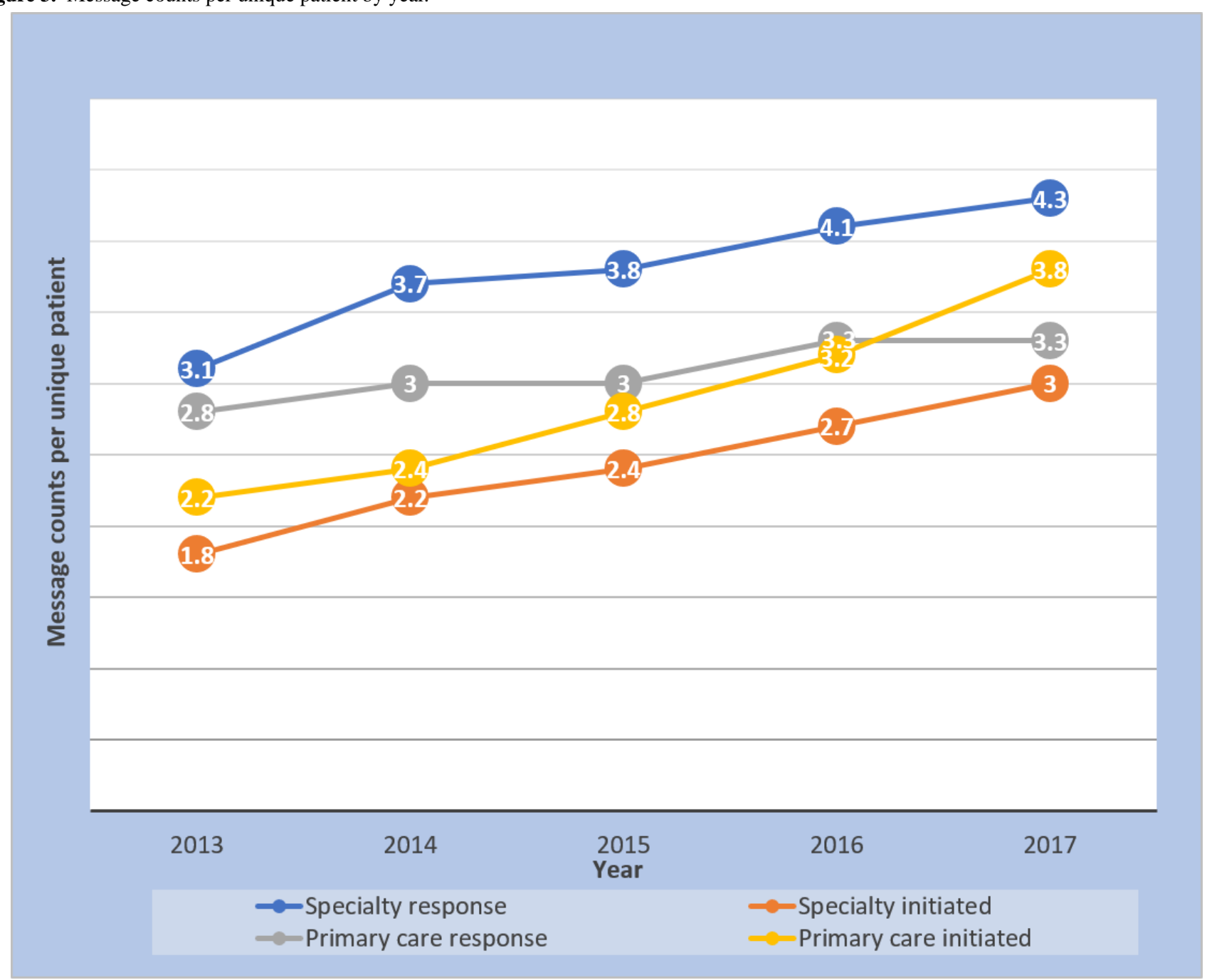

Table 2. Messages per unique patient by year.

\begin{tabular}{lllllll}
\hline Message type & \multicolumn{2}{l}{ Mean messages per unique patient by year (SD, 95\% CI) } & & \\
& 2013 & 2014 & 2015 & 2016 & 2017 & vvalue $^{\mathrm{a}}$ \\
\hline $\begin{array}{l}\text { Provider message responses from } \\
\text { all specialty and primary care }\end{array}$ & $3.6(5.3,3.5-3.6)$ & $4.2(6.6,4.1-4.2)$ & $4.3(6.3,4.3-4.3)$ & $4.7(6.7,4.6-4.7)$ & $4.9(6.9,4.9-4.9)$ & $<.001$ \\
$\begin{array}{l}\text { Provider-initiated messages from } \\
\text { all specialty and primary care }\end{array}$ & $2.1(2.0,2.1-2.1)$ & $2.5(2.7,2.5-2.5)$ & $2.8(3.1,2.8-2.8)$ & $3.2(3.6,3.2-3.3)$ & $3.7(4.1,3.7-3.7)$ & $<.001$ \\
\hline
\end{tabular}

${ }^{\mathrm{a}} \mathrm{H} 0$ : mean messages are equal across years. 
Figure 4. Message responses in primary care per provider by year.

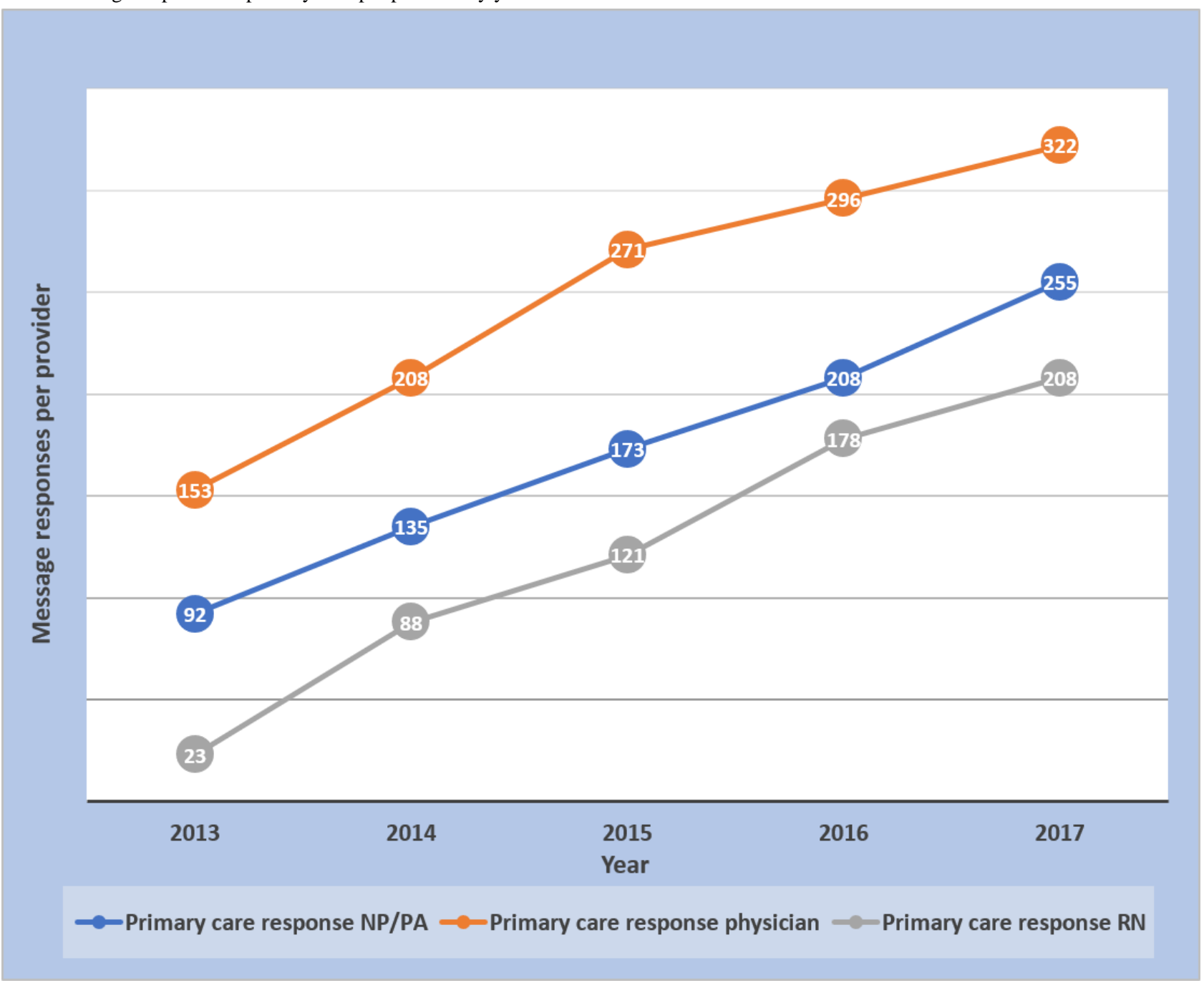


Figure 5. Message responses in specialty care per provider by year.

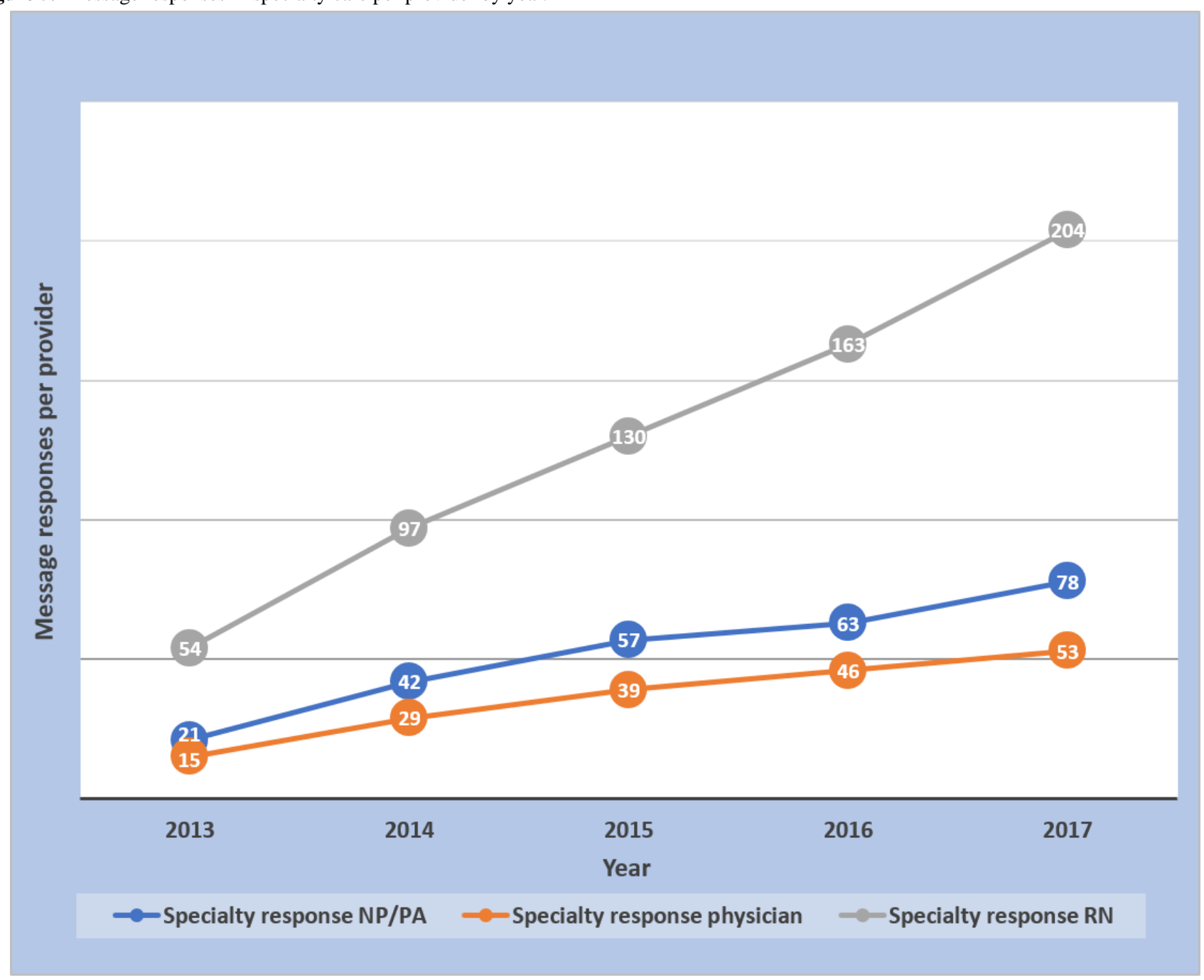

Tables 3 and 4 show that the number of unique patients receiving provider message responses increased from $133 \%$ to $1215 \%$ across provider groups. Some of this increase could be attributed to more patients having access to secure messages. During the same 5-year interval, there was an $88 \%$ increase in portal registration (33\% registered in 2013 to $62 \%$ in 2017). In contrast, the average number of provider-response messages per unique patient increased by at most $21 \%$ across provider groups. Nurses had the largest increases in messages per provider in both primary care (804\%) and specialty care (278\%). The percentage of messages completed after hours increased or decreased depending on the provider group, as shown in more detail (Tables 3 and 4). However, across all provider groups, there were more messages per provider completed after hours in 2017 than in 2013 (Tables 3 and 4).

Figure 6 shows the change in work distribution for responding to messages over 5 years. Statistical analysis using the Cochran-Armitage test for trend for the data in Figure 6 showed that there were statistically significant downtrends in the percentage of message responses completed by physicians as well as other $(P<.001)$. There were also statistically significant uptrends in the percentage of message responses completed by nurses and NP/PAs $(P<.001)$.

Figure 7 shows the percentage of messages completed after hours by staff type and year. Statistical analysis using the Cochran-Armitage test for trend of the data shown in Figure 7 showed that the percentage of after-hours message responses trended up for primary care physicians and primary care NP/PAs from 2013 to 2018 (each with $P<.001$ ). There was no significant trend in after-hours specialty physician responses and primary care $\mathrm{RN}$ responses $(P=.10$ and $P=.11$, respectively). There was a significant downtrend for after-hours $\mathrm{RN}$ specialty responses and NP/PA specialty responses (each with $P<.001$ ). It should be noted that Mayo Clinic has salaried physicians, NP, and PA staff and does not base salary or any other compensation on the numbers of secure messages answered or initiated, whether during or after hours. However, for hourly compensated staff in nursing and other nonphysician/NP/PA staff, overtime work would be compensated. 
Table 3. Primary care messages.

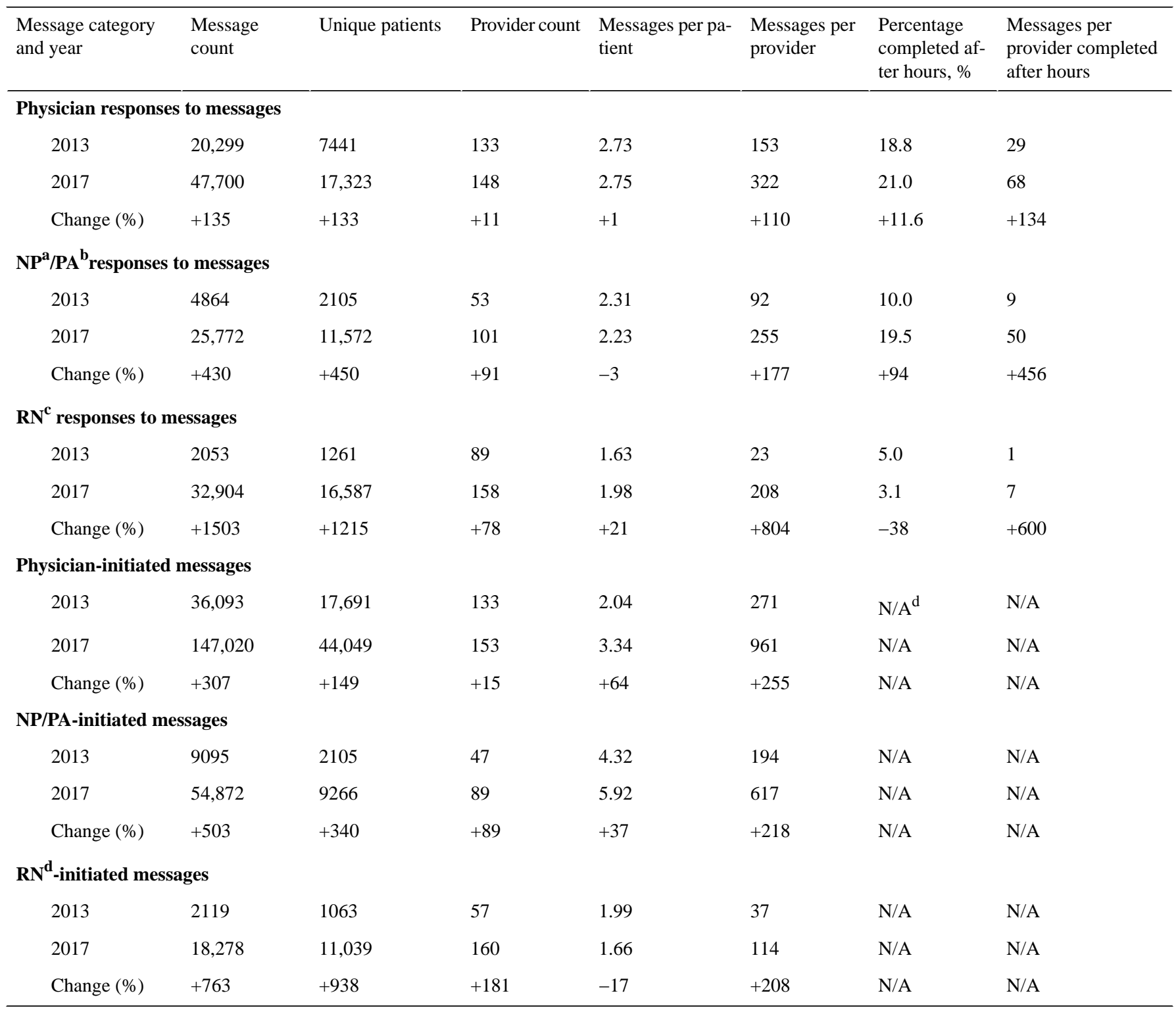

${ }^{\mathrm{a}} \mathrm{NP}$ : nurse practitioner.

${ }^{\mathrm{b}} \mathrm{PA}$ : physician assistant.

${ }^{\mathrm{c}} \mathrm{RN}$ : registered nurse.

${ }^{\mathrm{d}}$ N/A: not applicable. The percentage completed after work was not applicable in the provider-initiated messages because of the high percentage of automation. 
Table 4. Specialty care messages.

\begin{tabular}{|c|c|c|c|c|c|c|c|}
\hline $\begin{array}{l}\text { Message category } \\
\text { and year }\end{array}$ & $\begin{array}{l}\text { Message } \\
\text { count }\end{array}$ & Unique patients & Provider count & $\begin{array}{l}\text { Messages per pa- } \\
\text { tient }\end{array}$ & $\begin{array}{l}\text { Messages per } \\
\text { provider }\end{array}$ & $\begin{array}{l}\text { Percentage } \\
\text { completed af- } \\
\text { ter hours, \% }\end{array}$ & $\begin{array}{l}\text { Messages per } \\
\text { provider completed } \\
\text { after hours }\end{array}$ \\
\hline \multicolumn{8}{|c|}{ Physician responses to messages } \\
\hline 2013 & 19,919 & 7677 & 1337 & 2.59 & 15 & 21.0 & 3 \\
\hline 2017 & 104,624 & 36,825 & 1989 & 2.84 & 53 & 21.4 & 11 \\
\hline Change (\%) & +425 & +380 & +49 & +10 & +253 & +2 & +267 \\
\hline \multicolumn{8}{|c|}{$\mathrm{NP}^{\mathrm{a}} / \mathbf{P A}^{\mathrm{b}}$ responses to messages } \\
\hline 2013 & 4715 & 2103 & 229 & 2.24 & 21 & 10.9 & 2 \\
\hline 2017 & 28,668 & 12,542 & 369 & 2.29 & 78 & 10.2 & 8 \\
\hline Change (\%) & +508 & +496 & +61 & +2 & +271 & -6 & +300 \\
\hline \multicolumn{8}{|c|}{$\mathrm{RN}^{\mathrm{c}}$ responses to messages } \\
\hline 2013 & 25,635 & 7966 & 475 & 3.22 & 54 & 8.5 & 5 \\
\hline 2017 & 157,478 & 42,892 & 772 & 3.67 & 204 & 6.2 & 13 \\
\hline Change (\%) & +514 & +438 & +63 & +14 & +278 & -27 & +160 \\
\hline \multicolumn{8}{|c|}{ Physician-initiated messages } \\
\hline 2013 & 20,711 & 13,982 & 993 & 1.48 & 21 & N/A & N/A \\
\hline 2017 & 189,997 & 92,503 & 2048 & 2.05 & 93 & N/A & N/A \\
\hline Change (\%) & +817 & +562 & +106 & +39 & +343 & N/A & N/A \\
\hline \multicolumn{8}{|c|}{ NP/PA-initiated messages } \\
\hline 2013 & 5867 & 4382 & 143 & 1.34 & 41 & N/A & N/A \\
\hline 2017 & 49,697 & 28,911 & 344 & 1.72 & 144 & N/A & N/A \\
\hline Change (\%) & +747 & +560 & +141 & +28 & +251 & N/A & N/A \\
\hline \multicolumn{8}{|c|}{ RN-initiated messages } \\
\hline 2013 & 14,616 & 6458 & 341 & 2.26 & 43 & N/A & N/A \\
\hline 2017 & 99,421 & 38,128 & 732 & 2.61 & 136 & N/A & N/A \\
\hline Change (\%) & +580 & +490 & +115 & +15 & +216 & N/A & N/A \\
\hline
\end{tabular}

${ }^{\mathrm{a}} \mathrm{NP}$ : nurse practitioner.

${ }^{\mathrm{b}} \mathrm{PA}$ : physician assistant.

${ }^{\mathrm{c}} \mathrm{RN}$ : registered nurse.

${ }^{\mathrm{d}} \mathrm{N} / \mathrm{A}$ : not applicable. 
Figure 6. Percentage staff distribution responding to patient messages by year.

总
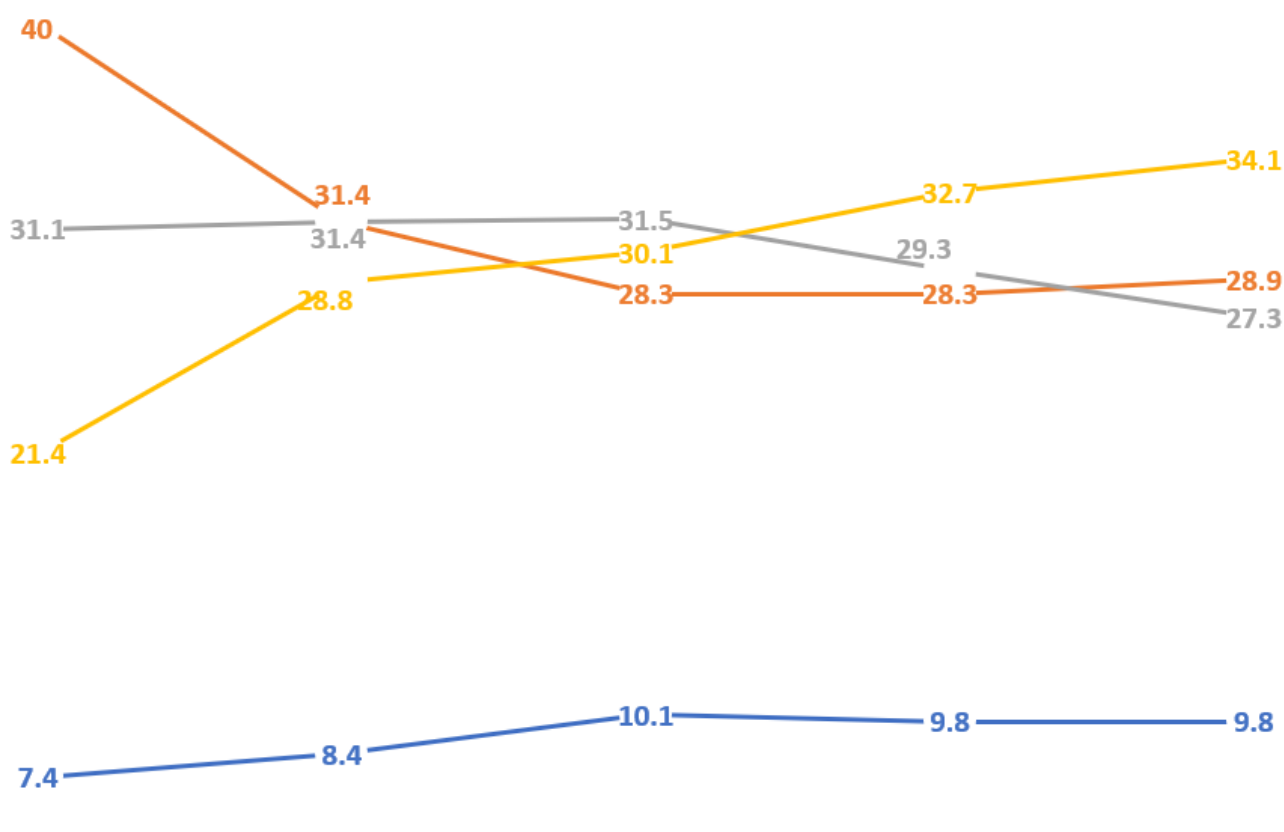

2013

2014

2015

2016

2017

$--N P / P A \quad--$ Other

- - Physician

$--\mathrm{RN}$ 
Figure 7. Percentage provider message responses outside of Monday-Friday 8 AM to 5 PM by year.
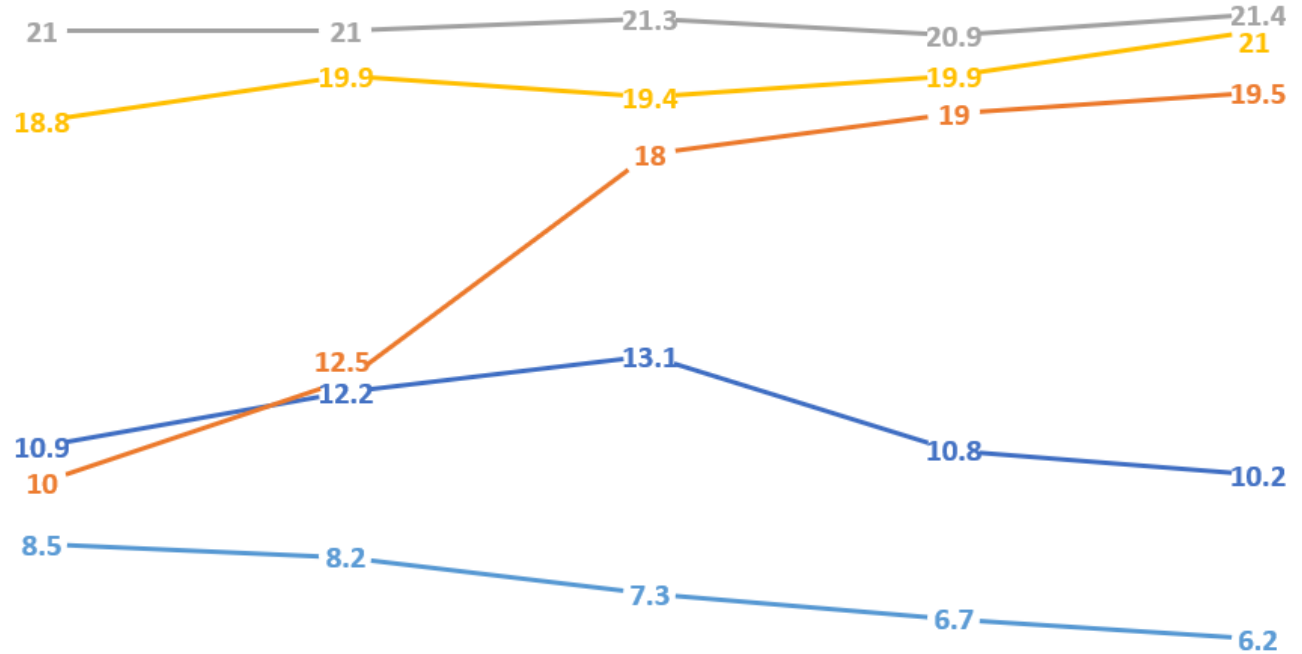

5

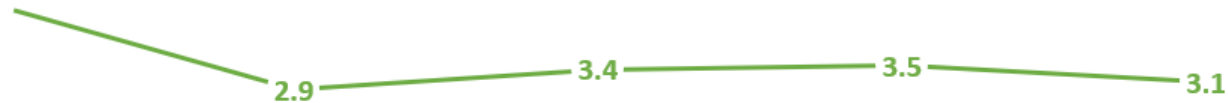

3.1

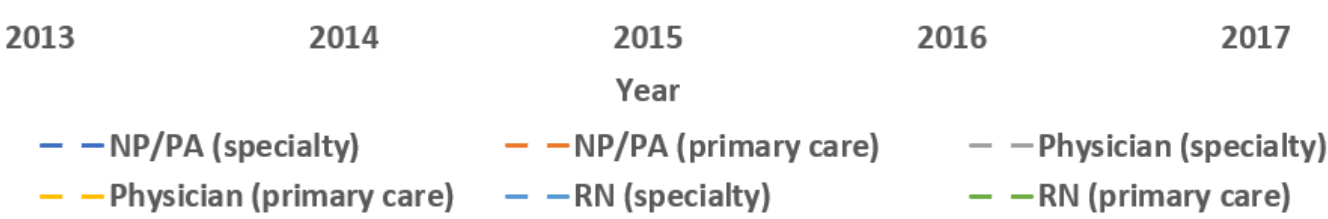

\section{Content Abstraction and Word Counts}

In the primary care provider-initiated messages, automated messages accounted for $66 \%, 53 \%$, and $18 \%$ of the physician, NP/PA, and nurse-initiated messages, respectively. For the specialty practice, automated messages accounted for $54 \%$, $47 \%$, and $13 \%$ of the physician, NP/PA, and nurse-initiated messages, respectively.

There were only a few provider-response messages that were limited to just an acknowledgment, such as "Thanks for the update." These acknowledgment messages accounted for only $2 \%, 1 \%$, and $1 \%$ of the primary care physician, NP/PA, and nurse response messages, respectively. Similarly, for specialty providers, brief acknowledgment messages accounted for $2 \%$, $6 \%$, and $3 \%$ of physician, NP/PA, and nurse response messages, respectively.

Our message content review revealed that provider-response messages sometimes included a reference to an additional provider who was involved in some way with the response. For the primary care providers, $2 \%, 1 \%$, and $24 \%$ of the respective physician, NP/PA, and nurse responses had evidence of involvement of another provider in the message response. With the specialty providers, other providers were involved in $1 \%$, $6 \%$, and $43 \%$ of the responses from physicians, NP/PA, and nurse responses, respectively. It should be noted that in our samples of 100 provider-response messages, we found no automated responses in the physician, NP/PA, or nurse messages responding to patient-initiated messages.

The median word counts from provider responses did not vary much over the course of the study; they remained just over 70 words for both the primary care and the specialty practices. Some of the word count was a standard signature that contained some packaged terms thanking patients for using the portal.

\section{Discussion}

\section{Principal Findings}

Both specialty and primary care practices experienced a large increase in the number of provider message responses as well as the number of provider-initiated messages to patients. There was no single provider category that took the brunt of the message volume increase. In fact, the provider categories of physicians, NP/PAs, RNs, and other all shared in handling the responses to patient messages. All these provider categories also shared in the increased volume of provider-initiated messages.

The large increase in message volume was not because of increases in patient visits. Patient visits increased by $<10 \%$, 
whereas during the same time, provider responses to messages increased by $288 \%$ in the primary care practice and $345 \%$ in the specialty practice. The rise in responses to patient messages was also much greater than the $88 \%$ increase in portal registration during that time. These facts support the finding that there was increasing provider engagement in messaging during the course of the study. That is, an increasing proportion of providers were responding to and sending messages. However, the message volume was not just driven by more providers messaging their patients; there were increases in message volumes per provider across the board (Figures 4 and 5). Messages per patient also increased in both primary and specialty care practices (Figure 3 and Table 2). Hoonakker et al and Wolcott et al [7,9] reported that patient messaging was associated with providers initiating messages. Perhaps the increase in provider-initiated messages encouraged individual patients to engage more frequently in secure messages.

Implementation of secure messages was staggered, with primary care starting in 2010 and specialty practices in 2013 . As a result, we had the opportunity to examine 62 months of secure message volumes for different time sequences. We observed specialty practice volumes for 62 months, starting from initiation in 2013 to 2018. As the primary care practice secure messages were implemented 3 years earlier (2010), the same 62 months encompassed years 4 to 9 of primary care message volumes. Over the same 62 months, but at different stages of experience with secure messages, secure message volumes showed continued growth both in primary care practice and in specialty practice. When separated into categories of provider message responses and provider-initiated messages, both categories showed a consistent rise over the 62 months.

\section{Work After Work}

In an ideas and opinion paper in the Annals of Internal Medicine, DiAngi et al [8] described some novel metrics for examining EHR use. This included a work after work metric that "captures the hours the clinician spends logged into the EHR during evenings, weekends, and vacations." The novel metrics also included what was termed fair pay, which are metrics that track "uncompensated EHR work, such as answering patient emails, providing medication refills..." [8]. Our study shows that approximately $20 \%$ of the time physicians completed message responses outside the usual business hours of $8 \mathrm{AM}$ to $5 \mathrm{PM}$. There was a statistically significant uptrend over time for primary care physicians; their after-hours messaging increased from $19 \%$ to $21 \%$, but not for specialty physicians whose after-hours messaging stayed stable between $21 \%$ and $22 \%$. This finding is similar to that of Arndt et al [10], who found that approximately $24 \%$ of the EHR work done by physicians (1.4 hours out of 5.9) occurred after hours. NP/PAs in the specialty practice also used after-work hours for approximately $12 \%$ of their message responses across the study period. The largest work after work increase was in the NP/PA category in primary care, whose percentage of messages sent after work hours increased from $10 \%$ to $19 \%$. The RN message responses, despite the increase in volume, had a statistically significant downtrend in percentage after-hours message completion.
As noted previously, physicians as well as the NP/PA staff are salaried, whereas a large number of nurses are on hourly wages. Although there was no statistically significant upward trend in percentage of message responses from specialty physicians completed after hours and only a couple of percentage points increase for primary care physicians, it remains that approximately $20 \%$ of these provider messages from physicians and primary care NP/PAs were sent after hours. There have been several papers associating EHR with burnout [11,12]. With the increase in secure messages, we thought that providers might be doing a larger percentage of the work after hours. Although there was a statistically significant increase in the percentage of after-hours messages completed by some provider groups, the rate of increase was low compared with the overall increase in the message volumes. However, because of the increase in message volume, all the provider groups completed more after-hours messages per provider in 2017 than in 2013 (Tables 3 and 4).

After data collection for this study was complete, Mayo Clinic switched to the Epic EHR. Epic has data collection methods that track message volumes and individual provider input (voice and keyboard) and can give management and providers feedback on the time spent in sending and receiving messages. This granular data about provider EHR activity throughout the day can be used to better identify the overall impact of messaging on provider workloads. The increase in provider secure messages shows the need for further investigations to examine the best practices in answering messages. In addition, the expanding role of secure messages needs to be considered in future studies of provider burnout.

In addition to continued examination of the work after work associated with secure messages, there is an opportunity to continue to assess how the increase in provider messaging may influence the tone of the messages. Hogan et al [13] evaluated some of the tone involved in these provider messages and noted that $25 \%$ of messages from health care team members appeared hurried. Newer informatics tools addressing sentiment analysis should help examine the content of portal messages and the sentiments associated with them [14].

\section{Practice Implications}

We found a high rate of growth of secure messages not attributable to increased patient visits, and the secure message growth continued to rise several years after implementation in primary care and specialty practices. Previous studies both at Mayo Clinic and elsewhere have demonstrated some of the effects of secure messages on subsequent face-to-face visits and some safety aspects related to secure messages [15-21], but we do not know all the ways that secure messages can affect the health care system. If secure messages cause a decrease in an equivalent volume of more time consuming, nonreimbursable telephone communication and letter correspondence, the increase in secure message volume may be a marker of increased efficiency. However, at least one study has shown no impact of messages on telephone message volume [22]. There is a need for further studies examining all forms of patient-provider communication, including the cost of telephone tag and transcription for letter correspondence to obtain a more 
comprehensive picture of the economic impact of secure messages [23].

Our study showed that large numbers of providers and patients are engaging in secure messages. From the provider standpoint, our study shows that this includes not only physicians but also large numbers of other providers, including nurses, NP/PA staff, and other groups. Nurses had the highest increases in message responses per provider and responded to more messages per provider in the specialty practice than the specialty physician and NP/PA groups combined (Figure 5). Regarding the division of work among staff, it deserves reemphasis that our content review found $43 \%$ of the specialty nurse responses, and $24 \%$ of the primary care nurse responses had evidence of input from another provider. Laccetti et al [24], who studied cancer center secure messages, also found a sizable percentage of messages was handled by nurses (29\%) and other nonphysician staff. As message volumes continue to rise, it will be important to efficiently divide the message responses among staff so that those that can be handled by nursing or other ancillary staff will not be sent to physicians. Cronin et al $[25,26]$ at Vanderbilt have been working on automating the important job of classifying and triaging patient messages. With the participation of multiple levels of staff in messages, our study underscores the importance of further examination of how secure messages are being used and the potential importance of trainable rules of engagement for different staff categories responding to messages [27].

These messages represent a new avenue to access medical care. Secure messages can be more convenient than telephonic services, which often have circumscribed hours of operation and can interpose several call transfers and waits between providers, care teams, receptionists, and patients. In addition, for many institutions, including Mayo Clinic, patient secure messages are answered free of charge. Thus, for those with web-based access, secure messages can be an attractive alternative to access a provider. Hospitalized patients are also now accessing secure messages through inpatient portals. Initial studies have shown that secure messages to providers in the hospital environment have not been as highly used by patients as other inpatient portal features [28]. However, nurses and other hospital staff have seen benefits from the inpatient portal, and there is new insight on how to best introduce the inpatient portal to hospitalized patients [29,30]. Hospitalized patients who are introduced to the inpatient portal may be more likely to engage in secure messages after hospital discharge when nurses are more than a few steps away [28].

Automated messages were a large part of the provider-initiated messages; at this point, there is limited data concerning the impact of these messages and patient acceptance of them. In addition, there were provider-response messages that indicated that more than one provider was involved in the message response. It will be important to understand the work that goes into these message responses as newer forms of payment for services are being considered.

Our study shows the need to carefully examine the economics and outcomes of secure message responses in both accountable care and fee-for-service models. The increasing message volume comes in the context of a fixed number of work hours. As more time is spent with messages, there will be increasing pressure on face-to-face time, regardless of the payment system. The increase in messages is likely to cause significant outcomes and economic impacts with either payment model.

\section{Limitations}

This study had several limitations. First, this was limited to one large multispecialty group located in North Central United States. The patients were mostly white and well educated, and the percentage of patients seen in the clinic who are registered on the portal increased to $62 \%$ over the course of the study. Our study also had a much higher rate of provider-initiated messages compared with a veteran's health administration study by Shimada et al [31], which showed that only $5.5 \%$ of messages were initiated by providers proactively reaching out to patients.

As seen in Table 1, there were changes in demographics of patients who were sending messages from the initiation of the study (early users of secure messages) to 5 years later. We did not perform an in-depth analysis of the demographics of face-to-face Mayo Clinic patients simultaneously at the same time points. It is possible that some of the longitudinal shift in demographics that we saw in patients using messages could be confounded by a 5-year demographic shift of all Mayo Clinic patients.

Our experience at Mayo Clinic in Rochester, Minnesota, may not be generalizable to other multispecialty groups. Mayo Clinic has a specialty care focus, and patients both nationally and internationally come to Mayo Clinic to receive highly specialized care. As seen in Table 1, approximately $40 \%$ of specialty response messages went to patients who did not live in Minnesota. The geographical distance of many of the Mayo specialty patients may encourage a higher use of secure messages compared with other multispecialty groups whose patients have fewer geographic barriers to face-to-face visits.

LPNs were also involved in some message responses and initiated messages but accounted for only $0.7 \%(12,680)$ of message responses and $1.6 \%(29,774)$ of initiated messages, so they were put in the other category. The staff responding to and initiating messages in the other category were generally secretaries and clinical assistants involved in scheduling; some of these messages did not have an associated identifier that we could assign to either primary care or specialty care. In addition, there were small percentages of nurses and NP/PAs who transferred from specialty to primary care or vice versa; our administrative data could not correct for these individual changes. However, these changes were likely limited to the RN and NP/PA groups, as physicians were constrained by physician specialty board certification.

\section{Conclusions}

In the first 8 years of secure message use in a large multispecialty group, secure message volumes showed large increases both in response to patient messages and provider-initiated secure messages. Both primary care practices and specialty practices saw large growth rates in total messages and messages per provider. Physicians, NP/PAs, and RNs all shared in responding to the increased volume of messages. 
Messages per unique patient also showed a significant increase over 5 years. The percentage of message responses after hours stayed close to $20 \%$ each year over 5 years for physicians in primary care and specialty practices.

\section{Authors' Contributions}

FN contributed to the study conception. FN, KL, EM, and TM contributed to the study design. FN, TM, and EM analyzed and interpreted the data and contributed to statistics. FN drafted the manuscript. FN, KL, TM, EM, ST, EN, and JP edited, critically revised, and approved the final version of the paper.

\section{Conflicts of Interest}

None declared.

\section{References}

1. National Cancer Institute. Health Information National Trends Survey: HINTS. 2013. Health Information Trends Survey Responses to Question 'In the Last 12 Months, Have You Used the Internet for Any of the Following Reasons' Used E-mail or the Internet to Communicate With a Doctor or Doctor's Office URL: https://hints.cancer.gov/view-questions-topics/ question-details.aspx?PK Cycle=6\&qid=761 [accessed 2020-05-05]

2. Lee JL, Choudhry NK, Wu AW, Matlin OS, Brennan TA, Shrank WH. Patient use of email, Facebook, and physician websites to communicate with physicians: a national online survey of retail pharmacy users. J Gen Intern Med 2016 Jan;31(1):45-51 [FREE Full text] [doi: 10.1007/s11606-015-3374-7] [Medline: 26105675]

3. Crotty BH, Tamrat Y, Mostaghimi A, Safran C, Landon BE. Patient-to-physician messaging: volume nearly tripled as more patients joined system, but per capita rate plateaued. Health Aff (Millwood) 2014 Oct;33(10):1817-1822 [FREE Full text] [doi: 10.1377/hlthaff.2013.1145] [Medline: 25288428]

4. Cronin RM, Davis SE, Shenson JA, Chen Q, Rosenbloom ST, Jackson GP. Growth of secure messaging through a patient portal as a form of outpatient interaction across clinical specialties. Appl Clin Inform 2015;6(2):288-304 [FREE Full text] [doi: 10.4338/ACI-2014-12-RA-0117] [Medline: 26171076]

5. Masterman M, Cronin R, Davis S, Shenson J, Jackson G. Adoption of secure messaging in a patient portal across pediatric specialties. AMIA Annu Symp Proc 2016;2016:1930-1939 [FREE Full text] [Medline: 28269952]

6. Shenson JA, Cronin RM, Davis SE, Chen Q, Jackson GP. Rapid growth in surgeons' use of secure messaging in a patient portal. Surg Endosc 2016 Apr;30(4):1432-1440 [FREE Full text] [doi: 10.1007/s00464-015-4347-y] [Medline: 26123340]

7. Hoonakker P, Carayon P, Cartmill R. The impact of secure messaging on workflow in primary care: results of a multiple-case, multiple-method study. Int J Med Inform 2017 Apr;100:63-76. [doi: 10.1016/j.ijmedinf.2017.01.004] [Medline: 28241939]

8. DiAngi YT, Lee TC, Sinsky CA, Bohman BD, Sharp CD. Novel metrics for improving professional fulfillment. Ann Intern Med 2017 Nov 21;167(10):740-741. [doi: 10.7326/M17-0658] [Medline: 29052698]

9. Wolcott V, Agarwal R, Nelson DA. Is provider secure messaging associated with patient messaging behavior? Evidence from the US army. J Med Internet Res 2017 Apr 6;19(4):e103 [FREE Full text] [doi: 10.2196/jmir.6804] [Medline: 28385681]

10. Arndt BG, Beasley JW, Watkinson MD, Temte JL, Tuan W, Sinsky CA, et al. Tethered to the EHR: primary care physician workload assessment using EHR event log data and time-motion observations. Ann Fam Med 2017 Sep;15(5):419-426 [FREE Full text] [doi: 10.1370/afm.2121] [Medline: 28893811]

11. Babbott S, Manwell LB, Brown R, Montague E, Williams E, Schwartz M, et al. Electronic medical records and physician stress in primary care: results from the MEMO study. J Am Med Inform Assoc 2014 Feb;21(e1):e100-e106 [FREE Full text] [doi: 10.1136/amiajnl-2013-001875] [Medline: 24005796]

12. Shanafelt TD, Dyrbye LN, Sinsky C, Hasan O, Satele D, Sloan J, et al. Relationship between clerical burden and characteristics of the electronic environment with physician burnout and professional satisfaction. Mayo Clin Proc 2016 Jul;91(7):836-848. [doi: 10.1016/j.mayocp.2016.05.007] [Medline: 27313121]

13. Hogan TP, Luger TM, Volkman JE, Rocheleau M, Mueller N, Barker AM, et al. Patient centeredness in electronic communication: evaluation of patient-to-health care team secure messaging. J Med Internet Res 2018 Mar 8;20(3):e82 [FREE Full text] [doi: 10.2196/jmir.8801] [Medline: 29519774]

14. Han H, Zhang Y, Zhang J, Yang J, Zou X. Improving the performance of lexicon-based review sentiment analysis method by reducing additional introduced sentiment bias. PLoS One 2018;13(8):e0202523 [FREE Full text] [doi: 10.1371/journal.pone.0202523] [Medline: 30142154]

15. Markle Fondation. 2003. Americans Want Benefits of Personal Health Records URL: http://www.markle.org/publications/ 950-americans-want-benefits-personal-health-records [accessed 2020-04-15]

16. North F, Crane SJ, Chaudhry R, Ebbert JO, Ytterberg K, Tulledge-Scheitel SM, et al. Impact of patient portal secure messages and electronic visits on adult primary care office visits. Telemed J E Health 2014 Mar;20(3):192-198 [FREE Full text] [doi: 10.1089/tmj.2013.0097] [Medline: 24350803]

17. North F, Crane SJ, Stroebel RJ, Cha SS, Edell ES, Tulledge-Scheitel SM. Patient-generated secure messages and eVisits on a patient portal: are patients at risk? J Am Med Inform Assoc 2013;20(6):1143-1149 [FREE Full text] [doi: 10.1136/amiajnl-2012-001208] [Medline: 23703826] 
18. Palen TE, Ross C, Powers JD, Xu S. Association of online patient access to clinicians and medical records with use of clinical services. J Am Med Assoc 2012 Nov 21;308(19):2012-2019. [doi: 10.1001/jama.2012.14126] [Medline: 23168824]

19. Reed M, Graetz I, Gordon N, Fung V. Patient-initiated e-mails to providers: associations with out-of-pocket visit costs, and impact on care-seeking and health. Am J Manag Care 2015 Dec 1;21(12):e632-e639 [FREE Full text] [Medline: 26760425]

20. Zhou Y, Garrido T, Chin H, Wiesenthal A, Liang L. Patient access to an electronic health record with secure messaging: impact on primary care utilization. Am J Manag Care 2007 Jul;13(7):418-424 [FREE Full text] [Medline: 17620037]

21. Baer D. Patient-physician e-mail communication: the kaiser permanente experience. J Oncol Pract 2011 Jul;7(4):230-233 [FREE Full text] [doi: 10.1200/JOP.2011.000323] [Medline: 22043186]

22. Bergmo TS, Kummervold PE, Gammon D, Dahl LB. Electronic patient-provider communication: will it offset office visits and telephone consultations in primary care? Int J Med Inform 2005 Sep;74(9):705-710. [doi: 10.1016/j.ijmedinf.2005.06.002] [Medline: 16095961]

23. Goldzweig CL, Orshansky G, Paige NM, Towfigh AA, Haggstrom DA, Miake-Lye I, et al. Electronic patient portals: evidence on health outcomes, satisfaction, efficiency, and attitudes: a systematic review. Ann Intern Med 2013 Nov 19;159(10):677-687. [doi: 10.7326/0003-4819-159-10-201311190-00006] [Medline: 24247673]

24. Laccetti AL, Chen B, Cai J, Gates S, Xie Y, Lee SJ, et al. Increase in cancer center staff effort related to electronic patient portal use. J Oncol Pract 2016 Dec;12(12):e981-e990 [FREE Full text] [doi: 10.1200/JOP.2016.011817] [Medline: 27601511]

25. Cronin R, Fabbri D, Denny J, Jackson G. Automated classification of consumer health information needs in patient portal messages. AMIA Annu Symp Proc 2015;2015:1861-1870 [FREE Full text] [Medline: 26958285]

26. Cronin RM, Fabbri D, Denny JC, Rosenbloom ST, Jackson GP. A comparison of rule-based and machine learning approaches for classifying patient portal messages. Int J Med Inform 2017 Sep;105:110-120 [FREE Full text] [doi: 10.1016/j.ijmedinf.2017.06.004] [Medline: 28750904]

27. Sieck CJ, Hefner JL, Schnierle J, Florian H, Agarwal A, Rundell K, et al. The rules of engagement: perspectives on secure messaging from experienced ambulatory patient portal users. JMIR Med Inform 2017 Jul 4;5(3):e13 [FREE Full text] [doi: 10.2196/medinform.7516] [Medline: 28676467]

28. Huerta T, Fareed N, Hefner JL, Sieck CJ, Swoboda C, Taylor R, et al. Patient engagement as measured by inpatient portal use: methodology for log file analysis. J Med Internet Res 2019 Mar 25;21(3):e10957 [FREE Full text] [doi: 10.2196/10957] [Medline: 30907733]

29. Hefner J, Sieck C, McAlearney A. Training to optimize collaborative use of an inpatient portal. Appl Clin Inform 2018 Jul;9(3):558-564 [FREE Full text] [doi: 10.1055/s-0038-1666993] [Medline: 30045386]

30. Hefner JL, Sieck CJ, Walker DM, Huerta TR, McAlearney AS. System-wide inpatient portal implementation: survey of health care team perceptions. JMIR Med Inform 2017 Sep 14;5(3):e31 [FREE Full text] [doi: 10.2196/medinform.7707] [Medline: 28912115]

31. Shimada SL, Petrakis BA, Rothendler JA, Zirkle M, Zhao S, Feng H, et al. An analysis of patient-provider secure messaging at two veterans health administration medical centers: message content and resolution through secure messaging. J Am Med Inform Assoc 2017 Sep 1;24(5):942-949. [doi: 10.1093/jamia/ocx021] [Medline: 28371896]

\section{Abbreviations \\ EHR: electronic health record \\ LPN: licensed practical nurse \\ NP: nurse practitioner \\ PA: physician assistant \\ POS: Patient Online Services \\ $\mathbf{R N}$ : registered nurse}

Edited by J Hefner; submitted 24.11.19; peer-reviewed by N Drimer, A Klingberg, T Palen; comments to author 16.02.20; revised
version received 17.03.20; accepted 15.04.20; published 08.07.20
Please cite as:
North F, Luhman KE, Mallmann EA, Mallmann TJ, Tulledge-Scheitel SM, North EJ, Pecina JL
A Retrospective Analysis of Provider-to-Patient Secure Messages: How Much Are They Increasing, Who Is Doing the Work, and Is
the Work Happening After Hours?
JMIR Med Inform 2020;8(7):e16521
URL: $\underline{\text { https://medinform.jmir.org/2020/7/e16521 }}$
doi: $\underline{10.2196 / 16521}$
PMID: $\underline{32673238}$


CFrederick North, Kristine E Luhman, Eric A Mallmann, Toby J Mallmann, Sidna M Tulledge-Scheitel, Emily J North, Jennifer L Pecina. Originally published in JMIR Medical Informatics (http://medinform.jmir.org), 08.07.2020. This is an open-access article distributed under the terms of the Creative Commons Attribution License (https://creativecommons.org/licenses/by/4.0/), which permits unrestricted use, distribution, and reproduction in any medium, provided the original work, first published in JMIR Medical Informatics, is properly cited. The complete bibliographic information, a link to the original publication on http://medinform.jmir.org/, as well as this copyright and license information must be included. 